\title{
Distribution and larval breeding habitats of Aedes mosquito species in residential areas of northwest Ethiopia
}

\author{
Getachew Ferede', Moges Tiruneh ${ }^{1}$, Ebba Abate ${ }^{2}$, Wondmeneh Jemberie Kassa ${ }^{3}$, \\ Yitayih Wondimeneh', Demekech Damtie ${ }^{4}$, Belay Tessema ${ }^{1}$ \\ 'Department of Medical Microbiology, School of Biomedical and Laboratory Sciences, College of Medicine and Health Sciences, University \\ of Gondar, Gondar, Ethiopia; ${ }^{2}$ Ethiopian Public Health Institute, Addis Ababa, Ethiopia; ${ }^{3}$ Department of Biology, College of Natural and \\ Computational Sciences, University of Gondar, Gondar, Ethiopia; ${ }^{4}$ Armauer Hansen Research Institute, Addis Ababa, Ethiopia
}

\begin{abstract}
OBJECTIVES: The Aedes mosquito is a vector for transmitting many arboviruses. Knowledge of the breeding habitat of this vector is vital for implementing appropriate interventions. Thus, this study was conducted to determine the breeding habitats and presence of Aedes mosquito species in the study areas.

METHODS: A house-to-house cross-sectional survey of Aedes mosquito breeding habitats was carried out in Metema and Humera, Ethiopia, in August 2017. All available water-holding containers present in and around houses were inspected for the presence of immature stages of Aedes mosquitoes, and they were collected and reared to the adult stage for species identification. In the larval survey, the house index, container index, and Breteau index were computed as risk indices.

RESULTS: Of the 384 houses surveyed for the presence of Aedes mosquito larval breeding, 98 were found to be positive for larvae. During the survey, a total of 566 containers were inspected, of which 186 were found to be infested with Aedes mosquito larvae, with a container index of 32.9, a house index of 25.5, and a Breteau index of 48.4. The most common Aedes mosquito breeding habitats were discarded tires (57.5\%), followed by mud pots (30.0\%). Of the 1,077 larvae and pupae collected and reared, Aedes aegypti (49.3\%), Ae. vittatus (6.5\%), and Culex species (44.2\%) were identified.
\end{abstract}

CONCLUSIONS: Discarded tires were the most preferred breeding habitats for Aedes mosquitoes. Moreover, Ae. aegypti, the main vector of dengue and other arboviruses, was identified for the first time in this region, suggesting a high potential for arbovirus transmission in the study areas.

KEY WORDS: Aedes mosquito, Breeding habitat, Risk indices, Arbovirus, Northwest Ethiopia

\section{Correspondence: Getachew Ferede}

Department of Medical Microbiology, School of Biomedical and Laboratory Sciences, College of Medicine and Health Sciences, University of Gondar, P,O, Box 196, Gondar, Ethiopia

E-mail: get29f@gmail.com

Received: Feb 14, 2018 / Accepted: Apr 22, 2018 / Published: Apr 23, 2018

This article is available from: http://e-epih.org/

(C) This is an open-access article distributed under the terms of the Creative Commons Attribution License (http://creativecommons.org/licenses/by/4.0/), which permits unrestricted use, distribution, and reproduction in any medium, provided the original work is properly cited.

(C) 2018, Korean Society of Epidemiology

\section{INTRODUCTION}

The Aedes mosquito is responsible for the transmission of many arthropod-borne viruses (arboviruses), including dengue virus, yellow fever virus, Zika virus, and chikungunya virus [1]. These arboviruses pose increasing global public health concerns because of their rapid geographical spread and increasing disease burden. In particular, dengue is the most important arboviral disease, and is widely distributed in the tropical and sub-tropical regions of the world [2]. The problem of dengue has now extended to areas where it has not been reported earlier, including Ethiopia, where the first outbreak was reported in Dire Dawa and the Somalia region $[3,4]$. 
Moreover, the reemergence of yellow fever in Ethiopia after 50 years was also recently reported [5]. These diseases can only persist where their respective vectors (Aedes mosquitoes) are present. Several factors can facilitate the global expansion of these arboviruses, such as increasing uncontrolled urbanization and human population growth, the lack of proper waste management, and inadequate vector control measures [6]. Increased international travel and trade can move viruses and Aedes mosquitoes from one part of the globe to another, thus increasing arbovirus outbreak risks $[7,8]$.

Infected female Aedes mosquitoes, mainly Aedes aegypti (Linnaeus) and also Ae. albopictus (Skuse), are the main vectors of several globally important arboviruses $[9,10]$. Ae. aegypti (Linnaeus) is currently distributed in urban areas and usually breeds in indoor and outdoor settings in a wide variety of natural and artificial water-holding containers such as plastic tanks, leaves, water storage jars, cement tanks, flower vases, curing tanks, glasses, rubber tires, and plastic bottles. Breeding habitats in urban areas arise mostly from neglected areas of construction sites and stagnant water that can create favorable conditions for mosquitoes to breed $[11,12]$. The destruction of Aedes mosquitoes breeding habitats reduces larval development, as well as the adult mosquito population and arbovirus transmission.

Most arboviral disease outbreaks occur during the rainy season and are associated with environmental factors such as rainfall, humidity, and temperature. These play a significant role in the transmission of arboviruses $[13,14]$. The likelihood of Aedes mosquitomediated outbreaks can be predicted by the use of risk indices such as the house index (HI), container index (CI), and Breteau index (BI) [12]. These indices are based on the simple determination of the presence or absence of Aedes mosquito larvae either in individual containers or somewhere in each house. These indices indicate the presence of Aedes mosquitoes and the potential risk of arboviruses and can be used to deploy appropriate interventions for the control of arboviral infections [15]. In particular, they can be used to support strategies for managing the population of Aedes mosquito larvae by releasing larvivorous predators into the collected water, eliminating breeding container habitats, and/or using insecticides [16]. Thus, knowledge of where Aedes mosquitoes breed is necessary for the implementation of effective control measures through larval control $[17,18]$.

In countries neighboring Ethiopia, such as Sudan, Eritrea, Kenya, and Djibouti, various arboviral diseases have been reported [19-23]. Moreover, dengue outbreaks and yellow fever reemergence have recently been reported in Ethiopia [3,5]. Both towns included in the present study are on the border with Sudan, and many day laborers also migrate to these towns from different regions of Ethiopia in search of jobs linked with the large-scale farming of cash crops. Therefore, individuals infected with arboviruses such as dengue and yellow fever may disseminate the diseases in these towns, aided by the bites of Aedes mosquitoes. To control the emergence of such arboviral diseases, it is vital to control their respective vectors. However, there are no available data showing the presence or absence of Aedes mosquito species in the study areas. Therefore, this study aimed to provide the first baseline data on the presence of container-breeding Aedes mosquito larvae in various containers and to document the most predominant arbovirus vector (Aedes mosquito species) identified in the study areas. The evidence generated here will be vital for undertaking early prevention and control interventions.

\section{MATERIALS AND METHODS}

\section{Study area, design, and period}

A cross-sectional study was conducted in the towns of Metema and Humera in August 2017. Metema is located in northwest Ethiopia on the border with Sudan, $897 \mathrm{~km}$ north of Addis Ababa. This town has a latitude and a longitude of $12^{\circ} 58^{\prime} \mathrm{N} 36^{\circ} 12^{\prime} \mathrm{E}$, with an elevation of $685 \mathrm{~m}$ above sea level. Humera is also located in northwest Ethiopia, $974 \mathrm{~km}$ from Addis Ababa, in the western zone of the Tigray Regional State, bordered on the west by Sudan and on the north by the Tekezé River, which separates Ethiopia from Eritrea. This town has a latitude and a longitude of $14^{\circ} 18^{\prime} \mathrm{N} 36^{\circ} 37^{\prime} \mathrm{E}$ with an elevation of $602 \mathrm{~m}$ above sea level. Both study areas are among the most endemic areas for malaria in the country and are also among the most fertile agricultural zones, with large-scale farming of cash crops such as corn, sorghum, cotton, and sesame. In particular, the town of Metema serves as an important trade gateway between Sudan and the Amhara Region of Ethiopia.

\section{Data collection}

A house-to-house mosquito breeding habitat survey was conducted in both study areas. A total of 384 houses (179 in Metema and 205 in Humera) were included in the study. At the time of the study, Metema and Humera had 5,452 and 6,262 houses, respectively. The houses included in the study were selected by a systematic random sampling technique. From both towns, the first house was randomly included in the study. Thereafter, every 30th house was inspected for mosquito breeding in potential breeding habitats. The presence of immature stages of mosquitoes was visually evaluated in all water-holding containers present in indoor and outdoor areas and the premises of the houses (Figure 1). Outdoor areas were defined as the outside of the house, but confined to its immediate area (i.e., located within $10 \mathrm{~m}$ ).

The number and type of containers inspected were recorded, including information on which had or did not have immature stages of mosquitoes. Larvae and pupae presumed to be Aedes mosquitoes were collected using a plastic cup, a pipette, or a ladle. The entire contents of the various containers were emptied into a large plastic tray or pan and the immature specimens were picked out using a dropper. They were placed immediately in labeled specimen bottles with water filled from a water container after collection and transported to an entomology laboratory. All collected larvae and pupae were reared in the laboratory until adults emerged, and all adults that emerged from the pupae were collected and stored in vials and carefully classified by species according 


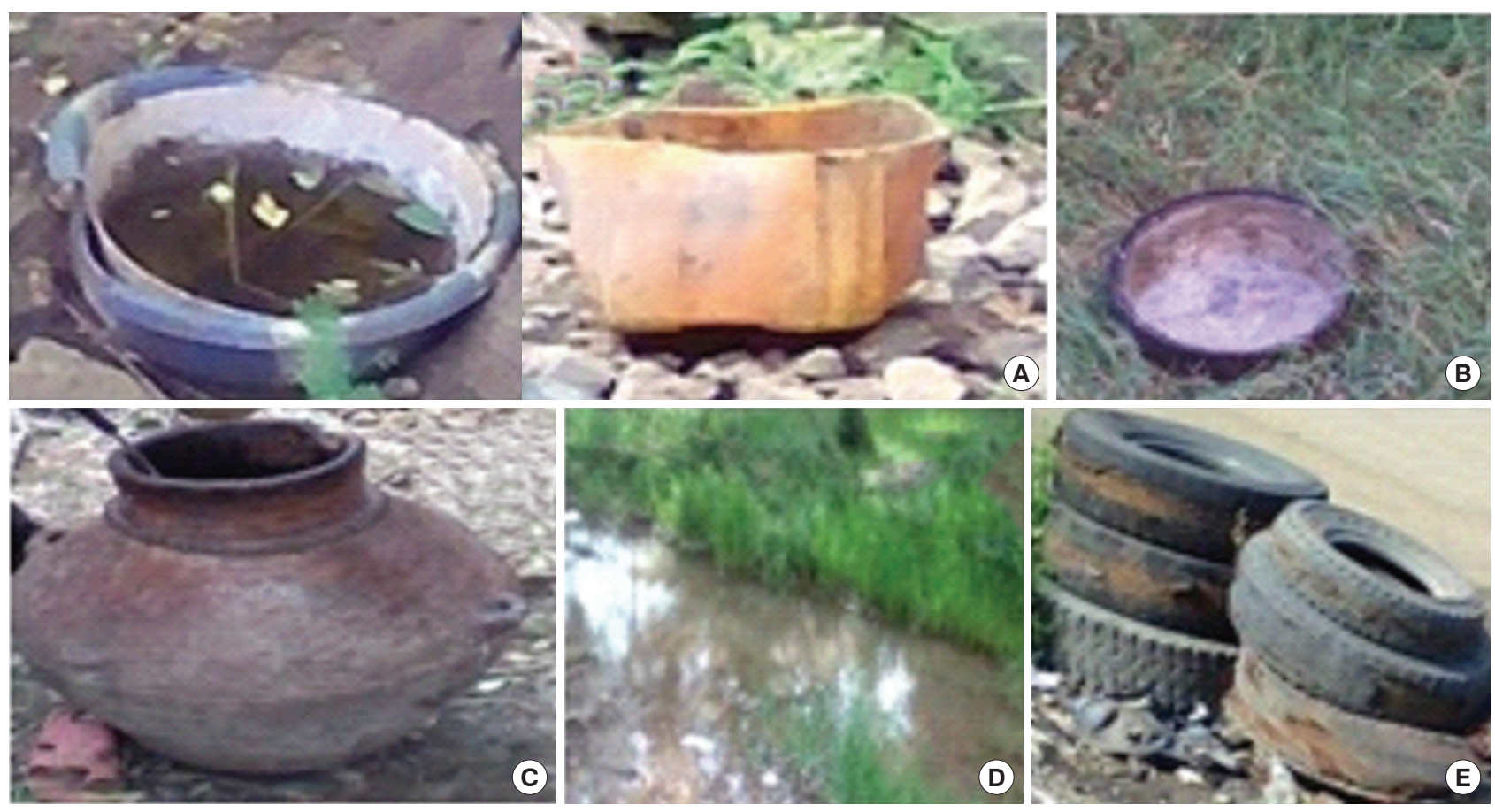

Figure 1. Aedes mosquito breeding habitats identified during a larval survey in the Ethiopian towns of Metema and Humera, (A) plastic containers, (B) mud dish, (C) mud pot, (D) ditch, and (E) discarded tires.

to the pattern of white bands, using a dissecting microscope and identification keys [24,25].

\section{Data analysis}

A descriptive analysis was conducted to calculate the proportions of various types of containers using Microsoft Excel 2007 (Microsoft Corp., Redmond, WA, USA). The risk indices HI, CI, and $\mathrm{BI}$ were calculated as follows:

$$
\begin{aligned}
& \mathrm{HI}=\frac{\text { Number of houses infested }}{\text { Total number of houses inspected }} \times 100 \\
& \mathrm{CI}=\frac{\text { Number of positive containers }}{\text { Total number of containers inspected }} \times 100[26,27] \\
& \mathrm{BI}=\frac{\text { Number of positive containers }}{\text { Total number of houses inspected }} \times 100
\end{aligned}
$$

According to the Pan American Health Organization and the World Health Organization (WHO), an area is at a high risk of arbovirus transmission when these indices are above the threshold of $5 \%$ for the $\mathrm{HI}$ and BI, and 3\% for the CI $[28,29]$.

\section{Ethical clearance}

The study was approved by the institutional review board of the University of Gondar. Informed consent was obtained from the owners/residents of each household prior to conducting the mosquito breeding site survey.

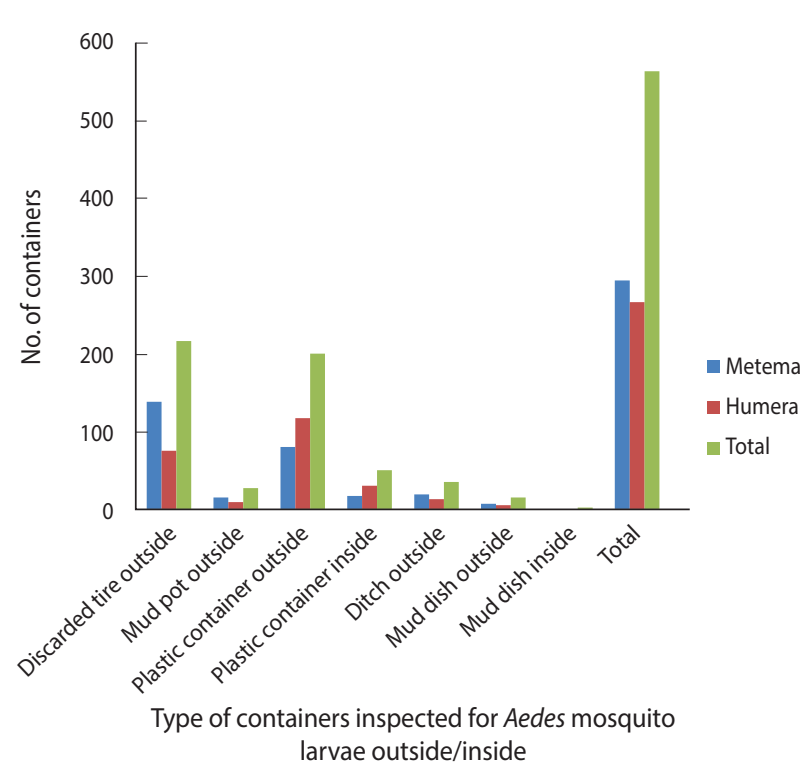

Figure 2. Water-holding containers inspected for Aedes mosquito larval breeding in the Ethiopian towns of Metema and Humera, August 2017.

\section{RESULTS}

\section{Aedes mosquito potential larval breeding habitats}

A total of 384 houses were surveyed, both outside and inside, in the towns of Metema and Humera to detect the presence of 
Aedes mosquito breeding sites. Overall, 566 water-holding containers were inspected during the survey (Figure 2), of which 186 (32.9\%) were found to be infested with Aedes mosquito larvae. The type of water-holding container in the study with the highest rate of positivity for Aedes mosquito larvae was discarded tires (57.5\%), followed by mud pots (30.0\%), mud dishes (21.7\%), ditches $(21.1 \%)$, and plastic containers (14.8\%). Aedes mosquito larval breeding was detected in all the listed types of water-holding containers that were found outside the homes (Figure 3).

\section{Aedes mosquito larval indices}

The BI, CI, and HI for Aedes mosquito larvae from both study areas were analyzed. Of the 384 houses surveyed, 98 had Aedes mosquito breeding habitats. The proportion of houses infested with Aedes mosquito larvae can be expressed as the HI, which was 25.5 in this study. Overall, 566 water-holding containers were identified, of which 186 had Aedes mosquito breeding. The CI was 32.9. The $\mathrm{BI}$, which reflects the number of positive containers per 100 houses inspected, was recorded as 48.4. Regarding specific study areas, 61 of the 179 houses inspected in Metema had Aedes mosquito breeding (HI, 34.1) while 297 containers were inspected, of which 127 had Aedes mosquito breeding (CI, 42.8). In the town of Humera, 37 of the 205 houses inspected had Aedes mosquito breeding (HI, 18). In this area, 269 containers were identified as water-holding containers, of which 59 were found positive for

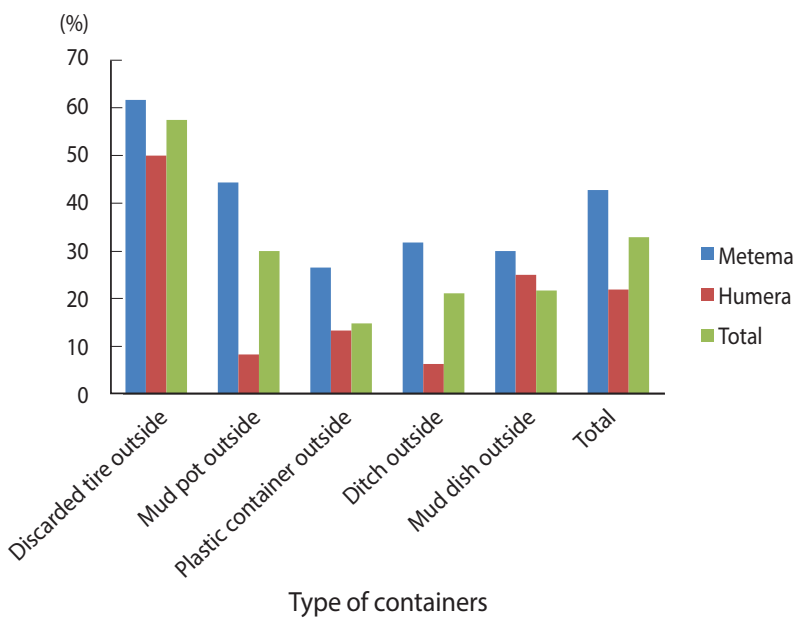

Figure 3. Distribution of containers infested with Aedes mosquito larvae in the Ethiopian towns of Metema and Humera, August 2017.
Aedes mosquito breeding (CI, 21.9). In Metema and Humera, BIs of 70.9 and 28.8 were recorded, respectively (Figures 4 and 5).

\section{Species of adult Aedes mosquitoes identified}

A total of 1,077 presumed Aedes mosquito larvae and pupae were collected from the 186 positive containers inspected and reared to the adult stage for species identification. Of these, 531 (49.3\%) were Ae. aegypti (Linnaeus), 70 (6.5\%) were Ae. vittatus (Bigot), and 476 (44.2\%) were Culex species. Ae. aegypti (Linnaeus)

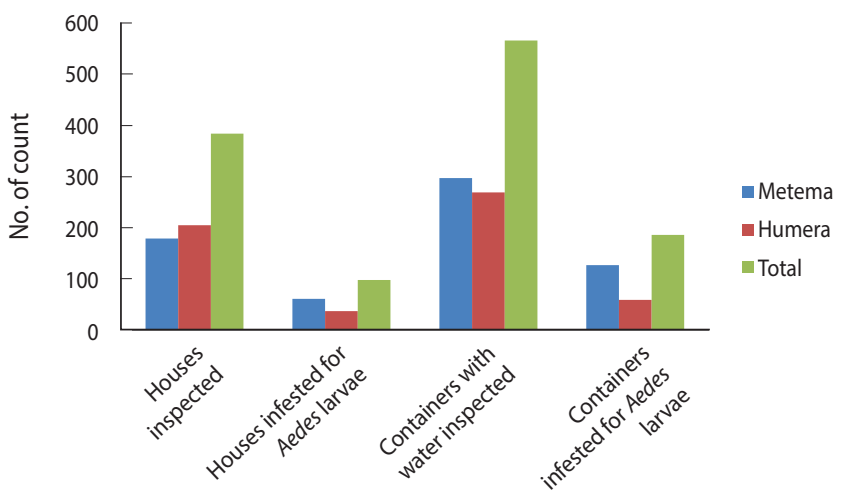

Figure 4. Houses and containers inspected for Aedes mosquito larval infestations in the Ethiopian towns of Metema and Humera, August 2017.

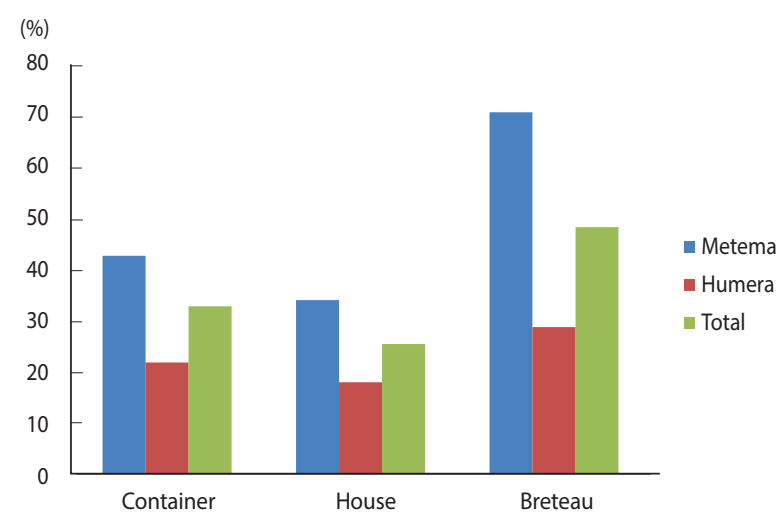

Figure 5. Container, house, and Breteau indices of Aedes mosquitoes in the Ethiopian towns of Metema and Humera, August 2017.

Table 1. Adult Aedes mosquito species identified from reared larvae and pupae in the Ethiopian towns of Metema and Humera, August 2017

\begin{tabular}{lccccc}
\hline Study area & $\begin{array}{c}\text { Containers positive for } \\
\text { larvae and pupae }\end{array}$ & $\begin{array}{c}\text { Larvae and pupae } \\
\text { collected }\end{array}$ & Aedes aegypti & Aedes vittatus & Culex species \\
\hline Metema & 127 & 760 & $409(53.8)$ & $25(3.3)$ & $326(42.9)$ \\
Humera & 59 & 317 & $122(38.5)$ & $45(14.2)$ & $150(47.3)$ \\
Total & 186 & 1,077 & $531(49.3)$ & $70(6.5)$ & $476(44.2)$ \\
\hline
\end{tabular}

Values are presented as number or number (\%). 
and Ae. vittatus (Bigot) were identified in both Metema and $\mathrm{Hu}-$ mera, suggesting a high risk of arbovirus transmission (Table 1).

\section{DISCUSSION}

In this study, discarded tires had an especially high positivity rate for larvae of Aedes mosquitoes. This is consistent with other studies done elsewhere [30-32]. This might have been because the water collected inside tires is not easily observable. Discarded tires might also be stored for longer durations and harbor mosquito larvae undisturbed, making them prolific breeding containers [33]. Moreover, the weather conditions inside tires, such as cool temperature, humidity, and reduced light, create a suitable environment for Aedes mosquito breeding [14,34]. Eggs attached to the tires also play a role in the preservation of the Aedes mosquito population throughout the off season [35]. This study showed that Aedes mosquitoes seemed to breed in containers found outside the homes, not inside, which is in agreement with another study [36]. However, contrasting results were reported by other studies $[37,38]$ that found that Ae. aegypti prefers to lay eggs and to rest indoors. A possible explanation for this discrepancy might be that many containers found outdoors are not mostly covered and filled with rainwater, and are therefore not ideal breeding sites for mosquitoes. These findings might have important implications for arbovirus vector control strategies, and in particular they may enable a more focused approach to vector control in which specific types of water-holding containers would be targeted. In such an approach, limited resources could be concentrated where they would have the greatest impact on disease transmission.

The presence of water-holding containers allows Aedes mosquito larvae to breed, thereby increasing the Aedes mosquito population and the concomitant risk for arbovirus transmission. In both areas in this study, the larval indices $\mathrm{HI}, \mathrm{CI}$, and BI, as indicated in Figure 5, were higher than the threshold values accepted by the Pan American Health Organization and WHO [28,29], but lower than those of a similar study in Dire Dawa, eastern Ethiopia in which the HI, CI, and BI were found to be 69.10, 54.00, and 134.55, respectively [39].The high observed values of the Aedes mosquito larval indices suggest a high risk of arbovirus transmission when arboviral cases become established in the area. Therefore, early interventions are necessary to combat the burden of emerging arboviral diseases.

In this study, the dominant Aedes mosquito species that emerged from the collected larvae was Ae. aegypti. This is in agreement with another study [39], and is also consistent with the preference of Ae. aegypti females to lay their eggs in domestic containers [40], but is in contrast with another study that identified Ae. albopictus as the most dominant species [41]. The presence of Ae. aegypti in this study is likely attributable to the abundance of suitable waterholding containers that are favorable for Ae. aegypti breeding and the availability of adequate organic material for its larval feeding [42]. This mosquito species is usually found in close proximity to human residences and feeds preferentially on human blood [43].
The strong preference for human blood exhibited by Ae. aegypti increases the potential for arbovirus transmission among humans. The second identified vector was Ae. vittatus, which is also a competent vector of arboviruses [44]. This Aedes mosquito species feeds on human and other animals, and this wide feeding behavior may somewhat limit its vectorial competency [45]. Future outbreaks of arboviral disease are possible in both areas included in this study due to the lack of native immunity in the population and the presence of Ae. aegypti, a major vector of arboviruses.

The study was the first attempt to characterize the presence of Aedes mosquitoes and their preferred breeding habitats in northwest Ethiopia. However, it has several limitations. The study was carried out during the rainy season, which might have led to high values of the risk indices. In all water-holding containers, the collected mosquito larvae and pupae were those presumed to be $A e-$ des mosquito larvae and pupae; for this reason, the species of mosquito larvae and pupae could not be conclusively identified. Biotic and abiotic factors and water quality, which might affect the oviposition preferences of vector mosquitoes, were not checked, and this could be done in the future. Despite these limitations, importantly, this preliminary study provides the first baseline data on the presence of the arbovirus vectors Aedes mosquitoes in the study areas.

In conclusion, this study found that discarded tires were the most preferred Aedes mosquito breeding habitats, followed by mud pots. Moreover, the study documented the presence of Ae. aegypti and Ae. vittatus in the study areas for the first time, suggesting a high risk of arbovirus transmission. Therefore, the breeding containers identified should be subjected to appropriate control measures, such as source reduction via the removal of water-holding containers around living and working areas, and proper disposal of tires should be implemented.

\section{ACKNOWLEDGEMENTS}

The authors would like to thank the University of Gondar for funding this research. We would also like to thank the Department of Biology, College of Natural and Computational Sciences, University of Gondar, for providing materials for larval collection and rearing.

\section{CONFLICT OF INTEREST}

The authors have no conflicts of interest to declare for this study.

\section{ORCID}

Getachew Ferede: https://orcid.org/0000-0001-9748-7326; Wondmeneh Jemberie Kassa: https://orcid.org/0000-0002-7545-9890

\section{REFERENCES}

1. Centers for Disease Control and Prevention. Zika virus [cited 2018 May 4]. Available from: https://www.cdc.gov/zika/preven- 
tion/index.html.

2. Rigau-Pérez JG, Clark GG, Gubler DJ, Reiter P, Sanders EJ, Vorndam AV. Dengue and dengue haemorrhagic fever. Lancet 1998; 352:971-977.

3. Woyessa AB, Mengesha M, Kassa W, Kifle E, Wondabeku M, Girmay A, et al. The first acute febrile illness investigation associated with dengue fever in Ethiopia, 2013: a descriptive analysis. Ethiop J Health Dev 2014;28:155-161.

4. Ahmed YM, Salah AA. Epidemiology of dengue fever in Ethiopian Somali region: retrospective health facility based study. Cent Afr J Public Health 2016;2:51-56.

5. Lilay A, Asamene N, Bekele A, Mengesha M, Wendabeku M, Tareke I, et al. Reemergence of yellow fever in Ethiopia after 50 years, 2013: epidemiological and entomological investigations. BMC Infect Dis 2017;17:343.

6. Gubler DJ. The economic burden of dengue. Am J Trop Med Hyg 2012;86:743-744.

7. Gubler DJ. Dengue, urbanization and globalization: the unholy trinity of the 21(st) century. Trop Med Health 2011;39(4 Suppl): 3-11.

8. Reiter P, Sprenger D. The used tire trade: a mechanism for the worldwide dispersal of container breeding mosquitoes. J Am Mosq Control Assoc 1987;3:494-501.

9. Gupta N, Srivastava S, Jain A, Chaturvedi UC. Dengue in India. Indian J Med Res 2012;136:373-390.

10. Gubler DJ. Dengue and dengue hemorrhagic fever. Clin Microbiol Rev 1998;11:480-496.

11. Chareonviriyaphap T, Akratanakul P, Nettanomsak S, Huntamai S. Larval habitats and distribution patterns of Aedes aegypti (Linnaeus) and Aedes albopictus (Skuse), in Thailand. Southeast Asian J Trop Med Public Health 2003;34:529-535.

12. Preechaporn W, Jaroensutasinee M, Jaroensutasinee K. The larval ecology of Aedes aegypti and Ae. albopictus in three topographical areas of Southern Thailand. Dengue Bull 2006;30:204-213.

13. Gould EA, Higgs S. Impact of climate change and other factors on emerging arbovirus diseases. Trans R Soc Trop Med Hyg 2009; 103:109-121.

14. Bi P, Zhang Y, Parton KA. Weather variables and Japanese encephalitis in the metropolitan area of Jinan city, China. J Infect 2007; 55:551-556.

15. Chan KL. Methods and indices used in the surveillance of dengue vectors. Mosq Borne Dis Bull 1985;1:79-88 (Japanese).

16. World Health Organization. Dengue: guidelines for diagnosis, treatment, prevention and control; 2009 [cited 2018 May 4]. Available from: http://www.who.int/tdr/publications/documents/dengue-diagnosis.pdf.

17. Kenawy MA, Ammar SE, Abdel-Rahman HA. Physico-chemical characteristics of the mosquito breeding water in two urban areas of Cairo Governorate, Egypt. J Entomol Acarol Res2013;45:e17.

18. Yap HH, Lee CY, Chong NL, Foo AE, Lim MP. Oviposition site preference of Aedes albopictus in the laboratory. J Am Mosq Control Assoc 1995;11:128-132.

19. Abdallah TM, Ali AA, Karsany MS, Adam I. Epidemiology of dengue infections in Kassala, Eastern Sudan. J Med Virol 2012; 84:500-503.

20. Watts DM, el-Tigani A, Botros BA, Salib AW, Olson JG, McCarthy $\mathrm{M}$, et al. Arthropod-borne viral infections associated with a fever outbreak in the northern province of Sudan. J Trop Med Hyg 1994;97:228-230.

21. Usman A, Ball JD, Rojas DP, Berhane A, Ghebrat Y, Mebrahtu G, et al. Dengue fever outbreaks in Eritrea, 2005-2015: a case for strengthening surveillance, control and reporting. Glob Health Res Policy 2016;1:17.

22. Ochieng C, Ahenda P, Vittor AY, Nyoka R, Gikunju S, Wachira C, et al. Seroprevalence of infections with dengue, Rift Valley fever and chikungunya viruses in Kenya, 2007. PLoS One 2015;10:e0132645.

23. Andayi F, Charrel RN, Kieffer A, Richet H, Pastorino B, LeparcGoffart I, et al. A sero-epidemiological study of arboviral fevers in Djibouti, Horn of Africa. PLoS Negl Trop Dis 2014;8:e3299.

24. Rueda LM. Pictorial keys for the identification of mosquitoes (Diptera: Culicidae) associated with dengue virus transmission. Zootaxa 2004;589;1-60.

25. Harrison BA. Field identification of adult and larval mosquitoes; 2005 [cited 2018 May 4]. Available from: http://www.gamosquito. org/resources/fguideid.pdf.

26. Webb CE. Mosquito ecology: field sampling methods. Aust Entomol 2008;47:382-383.

27. World Health Organization. Dengue haemorrhagic fever: diagnosis, treatment, prevention and control, 2nd ed; 1997 [cited 2018 May 4]. Available from: http://www.who.int/iris/handle/10665/41988.

28. Pan American Health Organization. Dengue and dengue hemorrhagic fever in the Americas: guidelines for prevention and control. Washington, DC: Pan American Health Organization; 1994, p. 9-10.

29. Rozendaal JA. Vector control: methods for use by individuals and communities; 1997 [cited 2018 May 4]. Available from: http:// www.who.int/iris/handle/10665/41968.

30. Vijayakumar K, Sudheesh Kumar TK, Nujum ZT, Umarul F, Kuriakose A. A study on container breeding mosquitoes with special reference to Aedes (Stegomyia) aegypti and Aedes albopictus in Thiruvananthapuram district, India. J Vector Borne Dis 2014; 51:27-32.

31. Singh S, Rahman A. Contribution of Aedes aegypti breeding by different income group communities of Dehradun city, Uttarakhand, India. Biol Forum Int J 2013;5:96-99.

32. Lloyd LS, Winch P, Ortega-Canto J, Kendall C. Results of a community-based Aedes aegypti control program in Merida, Yucatan, Mexico. Am J Trop Med Hyg 1992;46:635-642.

33. Snr S, Norma-Rashid Y, Sofian-Azirun M. Mosquitoes larval breeding habitat in urban and suburban areas, Peninsular Malaysia. World Acad Sci Eng Technol 2011;58:569-573.

34. Sripugdee S, Inmoung Y, Junggoth R. Impact of climate change on dengue hemorrhagic fever epidemics. Res J Appl Sci 2010;5: 260-262.

35. Rao BB, George B. Breeding patterns of Aedes stegomyia albopictus in periurban areas of Calicut, Kerala, India. Southeast Asian J 
Trop Med Public Health 2010;41:536-540.

36. Chareonviriyaphap T, Akratanakul P, Nettanomsak S, Huntamai S. Larval habitats and distribution patterns of Aedes aegypti (Linnaeus) and Aedes albopictus (Skuse), in Thailand. Southeast Asian J Trop Med Public Health 2003;34:529-535.

37. Luemoh A, McNeil D, Kuning M. Water consumption and distribution of dengue larvae in Pattani villages. Songkla Med J 2003; 21:209-216.

38. Thavara U, Tawatsin A, Chansang C, Kong-ngamsuk W, Paosriwong S, Boon-Long J, et al. Larval occurrence, oviposition behavior and biting activity of potential mosquito vectors of dengue on Samui Island, Thailand. J Vector Ecol 2001;26:172-180.

39. Getachew D, Tekie H, Gebre-Michael T, Balkew M, Mesfin A. Breeding sites of Aedes aegypti: potential dengue vectors in Dire Dawa, East Ethiopia. Interdiscip Perspect Infect Dis 2015;2015: 706276.

40. Dieng H, Saifur RG, Ahmad AH, Salmah MR, Aziz AT, Satho T, et al. Unusual developing sites of dengue vectors and potential epidemiological implications. Asian Pac J Trop Biomed 2012;2:
228-232.

41. Dom NC, Madzlan MF, Nur S, Hasnan A, Misran N. Water quality characteristics of dengue vectors breeding containers. Int J Mosq Res 2016;3:25-29.

42. Guagliardo SA, Barboza JL, Morrison AC, Astete H, Vazquez-Prokopec G, Kitron U. Patterns of geographic expansion of Aedes aegypti in the Peruvian Amazon. PLoS Negl Trop Dis 2014;8:e3033.

43. Ponlawat A, Harrington LC. Blood feeding patterns of Aedes aegypti and Aedes albopictus in Thailand. J Med Entomol 2005;42: 844-849.

44. Diagne CT, Faye O, Guerbois M, Knight R, Diallo D, Faye O, et al. Vector competence of Aedes aegypti and Aedes vittatus (Diptera: Culicidae) from Senegal and Cape Verde archipelago for West African lineages of chikungunya virus. Am J Trop Med Hyg 2014;91:635-641.

45. Barrera R, Bingham AM, Hassan HK, Amador M, Mackay AJ, Unnasch TR. Vertebrate hosts of Aedes aegypti and Aedes mediovittatus (Diptera: Culicidae) in rural Puerto Rico. J Med Entomol 2012;49:917-921. 